\title{
Failure of Spot Welds under In-plane Static Loading
}

\author{
by P. Wung, T. Walsh, A. Ourchane, W. Stewart and M. Jie
}

ABSTRACT-Under in-plane loading conditions, two independent modes contribute to the failure of a spot weld: the in-plane shear mode and the in-plane rotational mode. In this work, the failures of both modes under large static load are examined individually. To study the combined failure of these two modes, two special test coupons are designed. The first coupon contains one spot weld. The second coupon contains five spot welds. Tests conducted in this work show that a very simple force-based failure criterion can be used to predict the failure of a spot weld under large in-plane combined static loads. Current multiaxial failure theory cannot explain this combined failure. This force-based spot weld failure criterion fits current automotive industry needs for body shell finite element application very well.

KEY WORDS-Spot weld, force-based failure criterion, multi-spot weld test verification, spot weld crack, spot weld failure

To understand and accurately predict spot weld failure attracts both industrial and academic researchers' attention. Numerous efforts have been devoted to estimating the fatigue life of a spot weld. ${ }^{1-4}$ Few stress-based multiaxial failure criteria have been published ${ }^{5-7}$ for spot weld fatigue failure prediction. These criteria, in general, are concluded from high-cycle/low-stress fatigue tests. Spot weld failure criteria for low-cycle/high-stress (say, $10^{2}$ cycles at yield) or static loads are extremely rare.

In real structural designs, spot welds may fail after very low cycle or static loading. For instance, spot weld cracks are often found in auto body structures after few-hundred-cycles road tests or even in body structural component static tests. In either case, the above-mentioned fatigue research results cannot provide much design assistance. In 1998, Lee and colleagues ${ }^{8}$ developed a test fixture for spot weld combined load failure studies and found that a simple criterion could be used effectively for predicting statically loaded spot weld failure. In their work, spot weld failure due to the combined normal pull, bending peel and tensile shear was studied. However, spot weld failure with in-plane rotation was not considered. Actually, rotational failure of spot welds does exist in complex auto body structures. For instance, failure of a front body apron panel at an engine-mounting bracket

$P$. Wung is a Research Engineer, $T$. Walsh is a Manager, A. Ourchane is a Supervisor and W. Stewart is a Test Technologist, MD44 AEC Building, Ford Motor Company, Dearborn, MI 48121. M. Jie is a Graduate Student, University of Michigan at Dearborn, Dearborn, MI 48128.

Original manuscript submitted: August 14, 2000.

Final manuscript received: November 1, 2000. after only 256 cycles loading contained a spirally cracked spot weld (see Fig. 1). This crack seems to be due to the combined in-plane rotational failure and in-plane tensile failure. Because there is no failure criterion that can analyze this type of failure, spot weld in-plane loading failure is the focus of current work.

Due to geometric complexity and material nonhomogeneity, in a separate study it was found that about 5000 to 11000 quadratic solid elements are required to model a spot weld to obtain somewhat reliable stress distribution. A typical vehicle contains about 2500 to 4000 spot welds. Due to the limitations of computer and engineering costs, it is impractical to model each spot weld by solid elements. Currently, in the automotive industry, the most common method of modeling a spot weld is to use rigid-bar links. A spot weld, in spite of the fact that it is not a slender structure, is still modeled as a rigid bar with both end nodes staying on the midplane of the sheet metal. By definition, the dependent nodes of a rigid bar would follow the independent nodes in the specified degree of freedom, which artificially constrain the local deformation of the rigid bar in the coupled degree of freedom. Apparently, this modeling method cannot provide accurate strains and stresses in the vicinity of the spot weld, which makes the stress-based spot weld failure criteria questionable. For this reason, to develop a force-based failure criterion also becomes the focus of current work.

To support the finite element analysis requirements for spot weld design, fundamental research was conducted at the Ford Motor Company to establish a general force-based spot weld failure criterion. ${ }^{11}$ The work presented in this paper represents part of the work done in Ref. 11. In this work and in the work of Ref. 11, failure is defined as the "linear limit" of a given force/deflection curve. It is assumed that this choice of failure criterion will provide a good design guideline for the endurance of structures such as auto bodies. In addition, regardless of the metal thickness, a spot weld of only one size- $6.7 \mathrm{~mm}$ (0.2638 in.) in diameter-is studied in this work and in Ref. 11.

\section{Failure Rule}

It is assumed that a statically loaded spot weld will fail according to the following rule:

$$
\left(\frac{f_{s}}{F_{s}}\right)^{\alpha}+\left(\frac{m_{b}}{M_{b}}\right)^{\gamma}+\left(\frac{f_{n}}{F_{n}}\right)^{\mu}+\left(\frac{m_{t}}{M_{t}}\right)^{\beta}=1
$$

In this equation, $s, b, n$ and $t$ represent the four independent failure modes-tensile shear, peel bending, normal pull and in-plane torsion, respectively. The denominators $F_{s}$, $M_{b}, F_{n}$ and $M_{t}$ represent the spot weld strengths of the four 


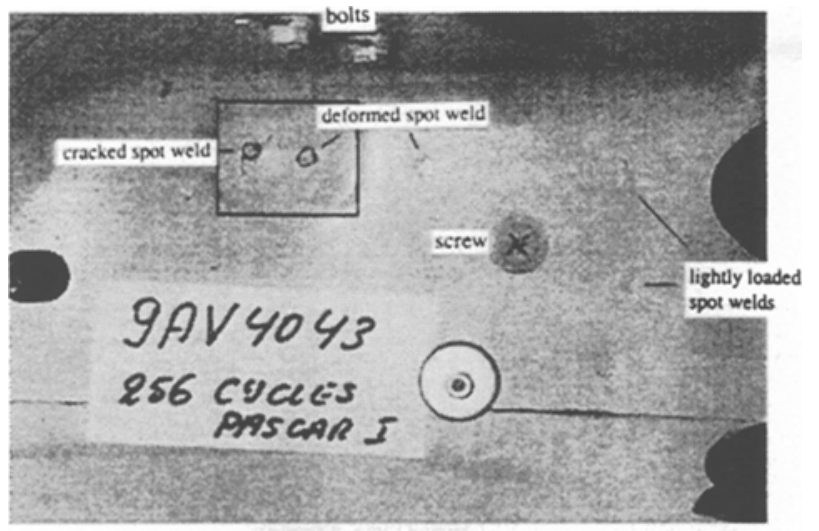

Fig. 1-Vehicle spot welds after loading

independent failure modes, respectively, and the numerators $f_{s}, m_{b}, f_{n}$ and $m_{t}$ represent the applied loads on the corresponding failure modes, respectively. The symbols $\alpha, \gamma, \mu$ and $\beta$ are the unknowns that would define the failure surface between the independent modes. In the absence of a bending mode and a normal mode, the above equation is reduced to

$$
\left(\frac{f_{s}}{F_{s}}\right)^{\alpha}+\left(\frac{m_{t}}{M_{t}}\right)^{\beta}=1 \text {. }
$$

\section{Tensile Test}

The tensile test coupon (see Fig. 2) is used to determine the shear strength. If the loading is applied symmetrically along the centerline of the specimen, a symmetric deformation will be produced. Under such a circumstance, the in-plane rotational deformation will not occur, and the failure equation becomes

$$
\left(\frac{f_{s}}{F_{s}}\right)^{\alpha}=1
$$

Regardless of the value of $\alpha$, this equation can always be satisfied whenever $f_{s}$ equals $F_{s}$.

When loaded with a large, monotonic static force, the tensile test coupon will produce an out-of-plane warping and demonstrate a lower strength. To prevent the out-of-plane warping, a U-shaped guide plate is used (see Fig. 2). When the U-shaped guide plate is installed around the spot weld, a nearly pure in-plane stretching deformation can be obtained. Tests show that before failure (i.e., the yield point or the linear limit of the force/extension curve), the guide plate does not influence the force/extension relationship. However, after failure, the guide plate will not only maintain the coupon flat but also increase the strength of the spot weld significantly (see Fig. 3). This is because without the guide plate, the spot weld is loaded by combined peel and the in-plane shear mode, but with the guide plate, the spot weld is loaded by the shear mode only.

The spot weld cracks developed by a tensile test are shown in Fig. 4, and some important fracture-associated phenomena can be observed:

- The fracture is the result of sheet metal necking on the thinner metal. It is not an inside-to-outside type of crack growth fracture such as that shown in Fig. 7.

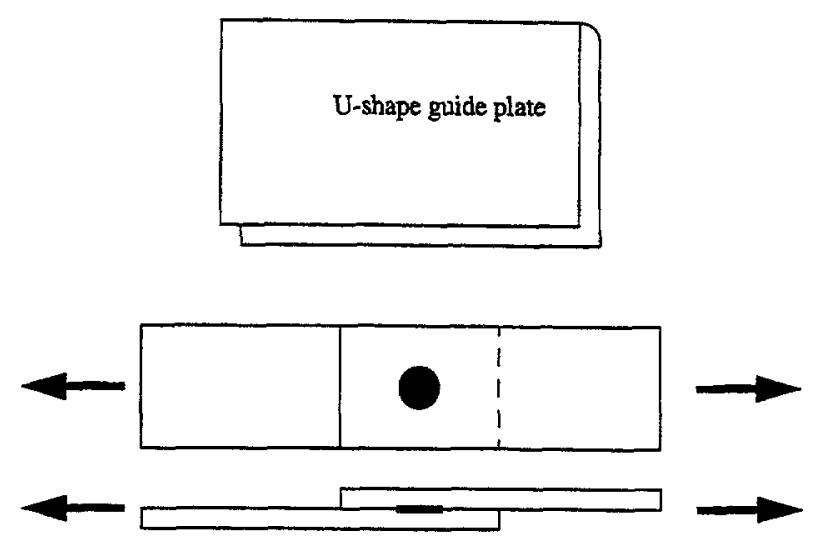

Fig. 2-Coupon for tensile test

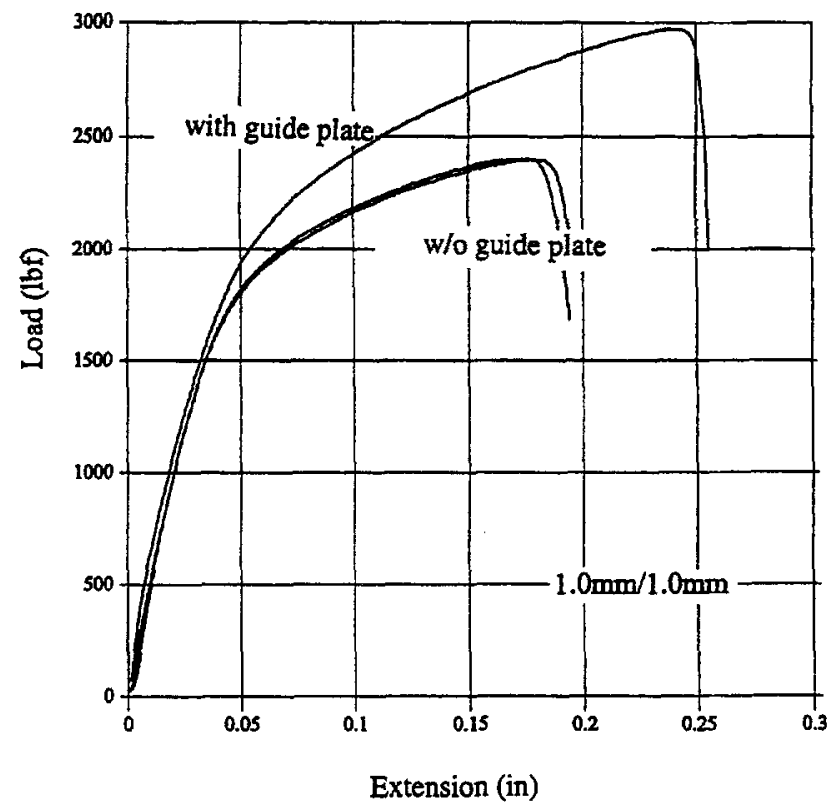

Fig. 3-Load/deflection curves of tensile tests with and without guide plate

- The necking is similar to the necking of ductile material in a standard sheet metal test, which demonstrates an approximately equal contraction from both sides of the sheet metal.

- The metal necking starts at the peak of the force/extension curve and continues its lateral contraction until the force drops about 15 percent from the peak, at which point the crack can be observed by the naked eye.

- Compression of the material occurs on the side of the spot weld opposite to the necking area.

- Both material compression and necking occur in the vicinity of the heat affect zone where the metallurgical structure changes due to large-strain energy redistribution.

- No out-of-plane deformation occurs in the nugget.

- The metallurgical structure of the nugget is maintained before and after the test, indicating that no shear deformation occurs at the nugget. 


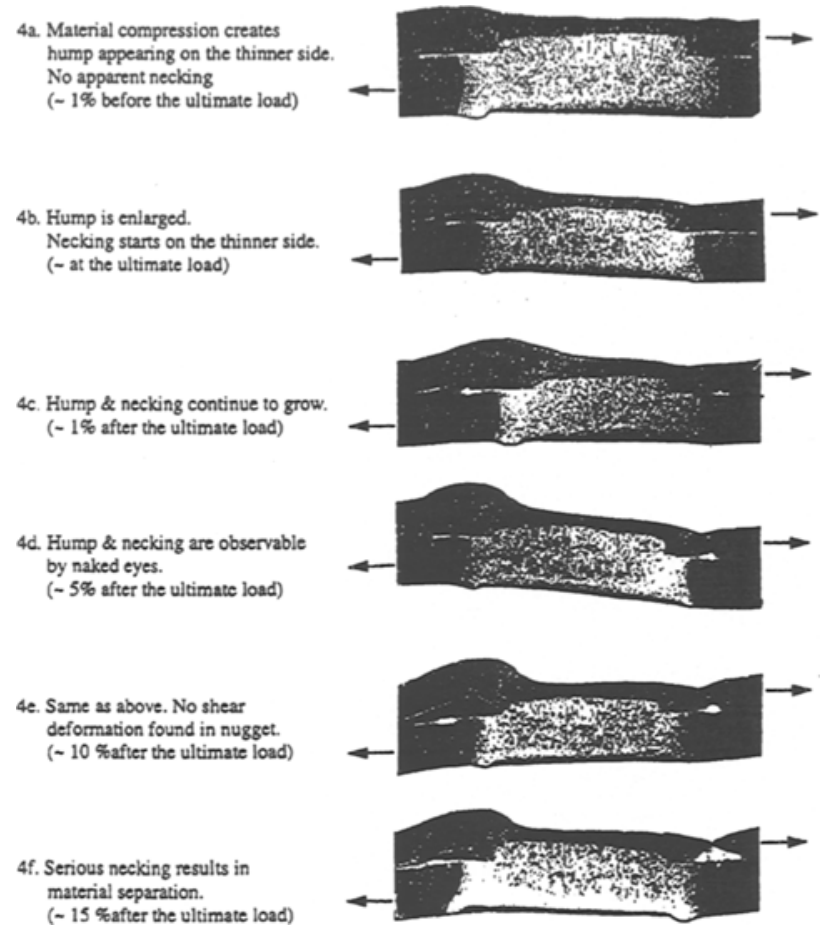

Fig. 4-Process of spot weld crack development under tensile tests

Eight different widths of tensile coupons were made and tested to determine the appropriate sample width for reliable results. The test results of $1.57 \mathrm{~mm} / 1.01 \mathrm{~mm}$ (0.0618 in./0.0398 in.) spot weld are shown in Fig. 5. From these tests, it was concluded that the force/deflection curves would approach a stable state asymptotically when the coupon width was equal to or greater than $35 \mathrm{~mm}$ (1.378 in.). Otherwise, the coupon would demonstrate an inconsistent "sheet metal" test. Based on this finding, two widths were used in the remainder of this work: $38 \mathrm{~mm}$ (1.5 in.) and $50.8 \mathrm{~mm}(2.0$ in.). With these widths, the shear strength $F_{s}$ for high-strength steel of $1.23 \mathrm{~mm} / 0.83 \mathrm{~mm}$ (0.0484 in. $/ 0.0327 \mathrm{in}$.) sheet metal and a $6.7 \mathrm{~mm}(0.2638 \mathrm{in}$.) diameter spot weld was found to be $5782 \mathrm{~N}$ ( $1300 \mathrm{lbf})$.

\section{In-plane Rotation Tests}

As introduced in Ref. 10, a scissors-type coupon (see Fig. 6) can be used to determine the strength of a spot weld under a nearly pure in-plane rotational load. The pinholes are designed to allow a complete free in-plane rotation at the spot weld tested.

When loaded in a tensile machine, a force/extension curve is obtained. The crack initiation, penetration and propagation due to in-plane rotational tests are shown in Fig. 7 , in which the test coupons are made of automotive mild steel. Details about this crack growth are described in Ref. 10.

The force/extension curves of an in-plane rotation test can be converted into a torque/angle curve using the following equations:

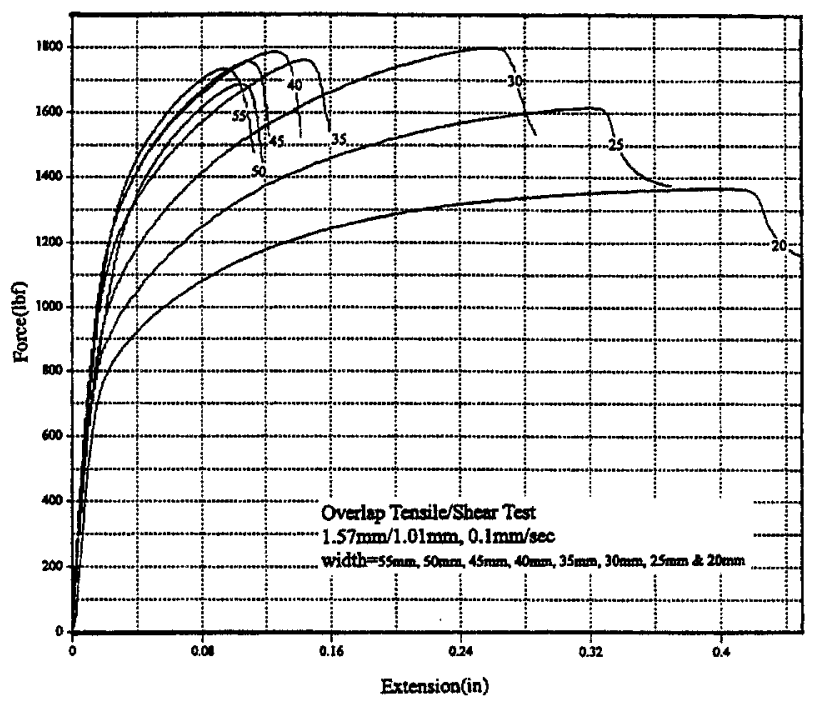

Fig. 5-Width study for tensile tests

$$
\begin{aligned}
\theta_{1} & =a \sin \left(\frac{S^{2}+L_{1}^{2}-L_{2}^{2}}{2 S L_{1}}\right) \\
\theta_{2} & =a \cos \left(\frac{L_{1}}{L_{2}} \cos \theta_{1}\right) \\
\theta & =\theta_{1}+\theta_{2} \\
\text { Torque } & =\text { Force } \times L_{1} \cos \theta_{1},
\end{aligned}
$$

where $L_{1}, L_{2}$ are the distances between the pinholes to the tested spot weld and $S$ is the distance between the pinholes (see Fig. 6). In a test, $L_{1}$ and $L_{2}$ are constant and $S$ (the distance between the pinholes) is changing. Substituting a new extension value $(S)$ and a new force into the previous set of equations, a force/extension curve can easily be converted into a torque/angle curve.

The simplest way to validate the correctness of the test fixture shown in Fig. 6 and the equations derived above is to put the same spot weld into different sizes of coupons. We used two sizes of scissors coupon with dimensions given in Table 1. The force/extension curves for these spot welds are shown in Fig. 8, which shows that the shorter coupons sustain higher loads than the longer coupons. After conversion, the resulting torque/angle curves (see Fig. 9) are much closer to each other for the same thickness spot welds compared with the force/extension curves. These tests prove that the in-plane rotational strength of a spot weld is nearly independent of the coupon size. The deformation is much localized in the heat affect zone. Therefore, the width study for this test becomes unnecessary.

Comparing Figs. 8 and 9 , it is evident that the peaks of torque/angle curves occur much earlier than the peaks of the force/extension curves. Because these two types of curves represent the same test, it would be interesting to know which peaks initiate the cracks. To answer this, both nondestructive and destructive examination techniques were used. Both the X-ray image and the electrical-discharged machine (EDM) cut microscope photos show that it is the ultimate 
Dimensions Vary to Fit Test
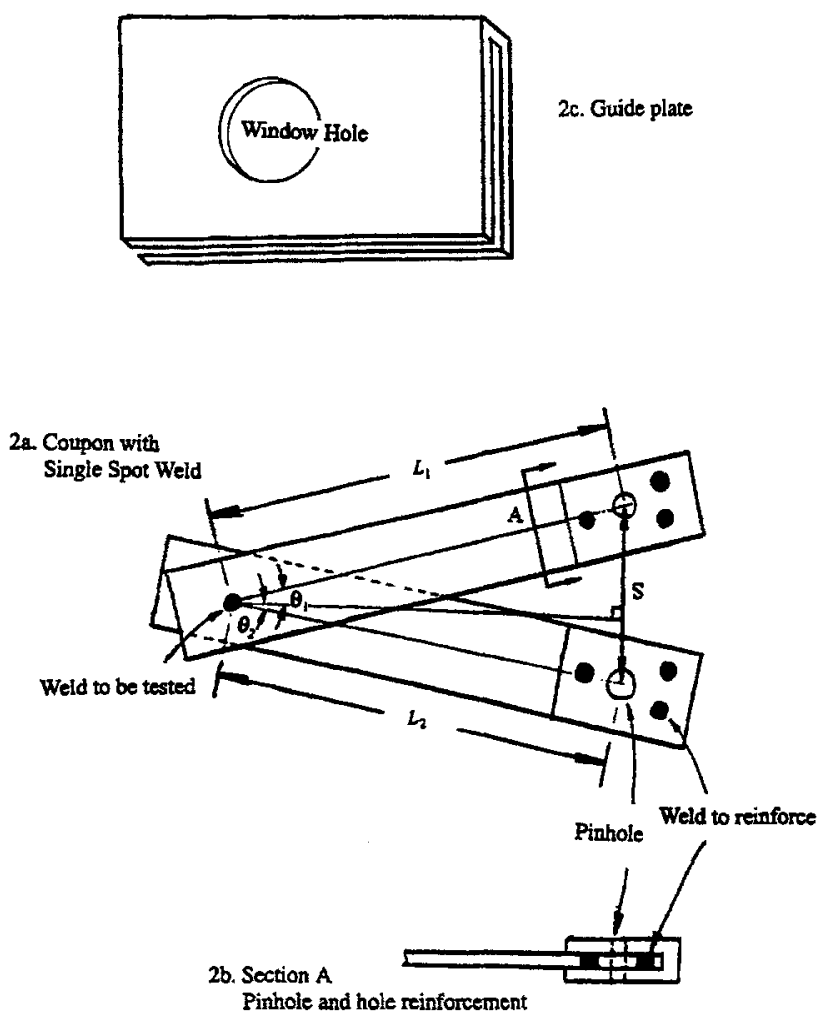

Fig. 6-Scissors coupon for in-plane rotation test

TABLE 1-DIFFERENT SIZES OF IN-PLANE ROTATIONAL TEST COUPONS

\begin{tabular}{lrrc}
\hline Thickness $(\mathrm{mm})$ & $L_{1}(\mathrm{~mm})$ & $L_{2}(\mathrm{~mm})$ & $S(\mathrm{~mm})$ \\
\hline $0.86 / 0.86$ short & 75.8 & 80.5 & 51.0 \\
$0.86 / 0.86$ long & 113.0 & 119.5 & 46.0 \\
$1.20 / 1.20$ short & 82.5 & 81.7 & 52.0 \\
$1.20 / 1.20$ long & 118.0 & 116.5 & 45.5
\end{tabular}

torque instead of the ultimate force that initiates the spot weld crack. Based on this finding, the spot weld in-plane rotational strength and the fracture can be determined and characterized. For instance, the high-strength $1.23 \mathrm{~mm} / 0.83 \mathrm{~mm}$ (0.0484 in./0.0327 in.) sheet metal with $6.7 \mathrm{~mm}(0.2638 \mathrm{in}$.) diameter spot weld yields an in-plane rotational strength $M_{t}$ of $16947 \mathrm{~N}-\mathrm{mm}$ (150 lbf-in.).

\section{Combined Load Test L-Offset Test}

As introduced above, the shear strength $F_{s}$ and the inplane rotational strength $M_{t}$ of a spot weld can be determined by a tensile test and an in-plane rotation test, respectively. However, the power indexes $\alpha$ and $\beta$ of the failure rule are still unknown. To determine these two indexes, an offset test can be used. This is shown in Fig. 10, where the straight line connecting the two pinholes defines the pure tensile load path. A spot weld located along this line will be subjected to a pure tensile failure as explained before.

When the tested spot weld is offset from the line connecting the pinholes, the spot weld will experience a combined tensile force and in-plane torque. The ratio between these two loadings depends on the amount of the offset. The more offset, the more rotational torque will be.

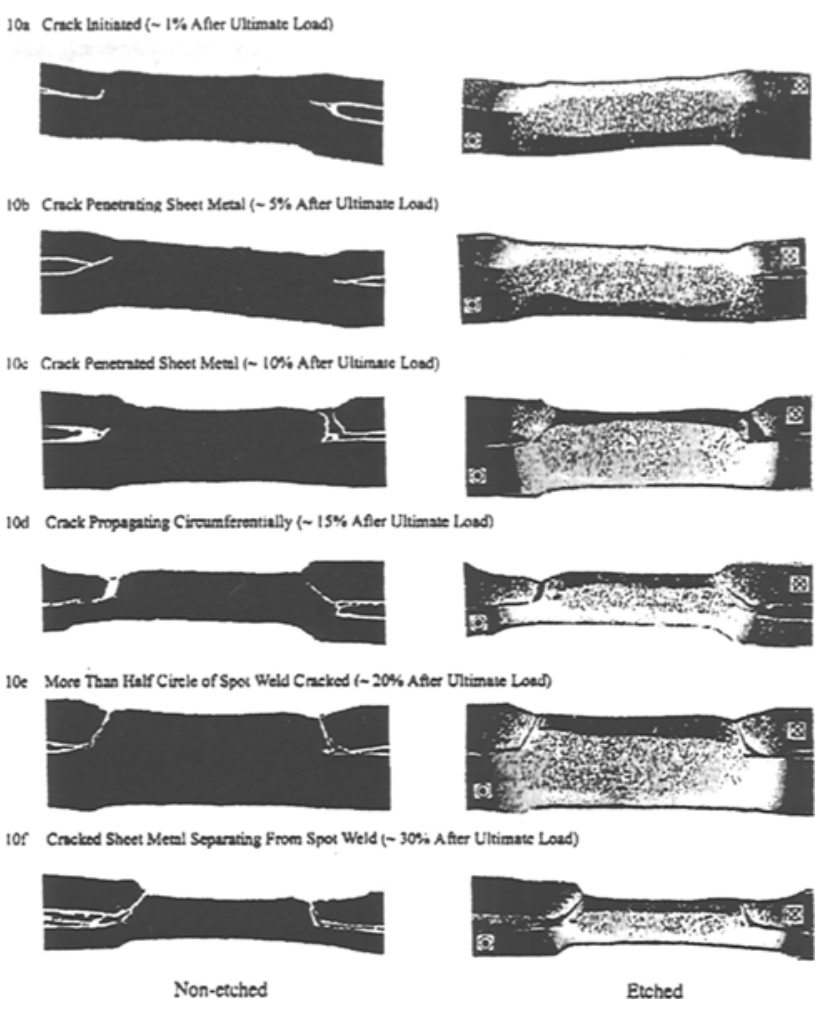

Fig. 7-Process of spot weld crack development under inplane rotation tests

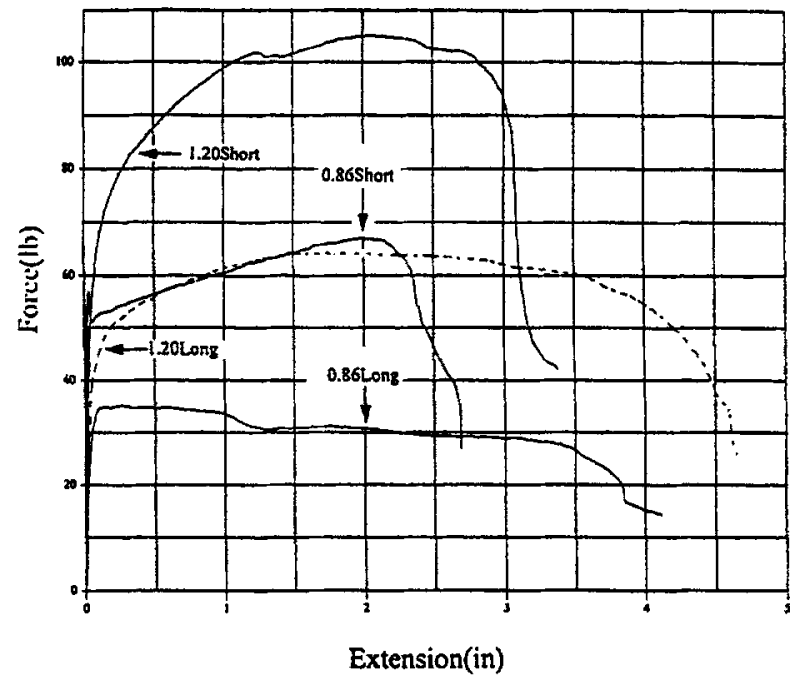

Fig. 8-Force/deflection curves of different sizes of in-plane rotation tests

The force/extension curves for different offsets of a $1.23 \mathrm{~mm} / 0.83 \mathrm{~mm}(0.0484 \mathrm{in} / 0.0327 \mathrm{in}$.) test are shown in Fig. 11. It is clear that bigger offsets produce lower yield points, even when the other conditions remain the same. When the offset is smaller than or equal to the radius of the spot weld, no in-plane rotational torque will be generated. In this case, an offset test becomes pure tensile. On the other hand, for some larger offsets, the curves are very close to the pure in-plane rotational tests. In Fig. 11, the offsets equal to $0.33 \mathrm{~mm}(0.013 \mathrm{in}$.$) and 1.67 \mathrm{~mm}(0.0657 \mathrm{in}$.) are parallel to each other and represent nearly the tensile tests. 


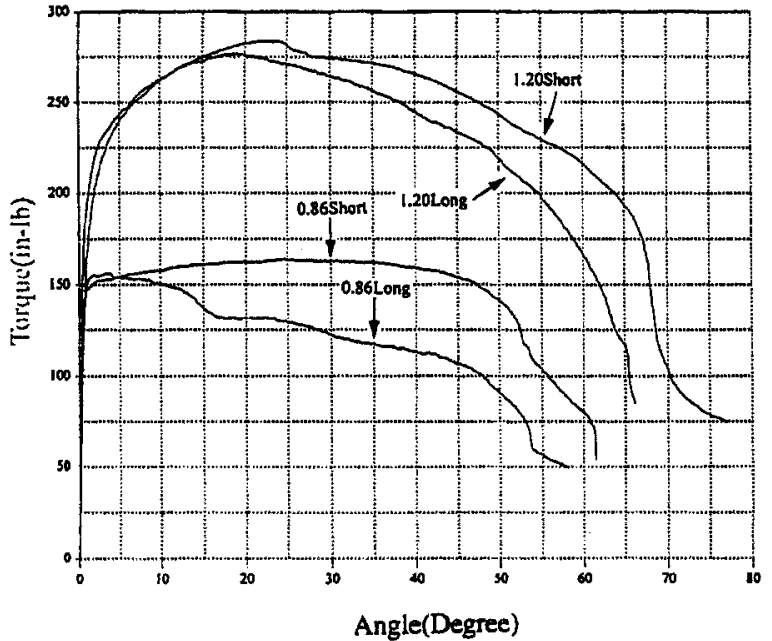

Fig. 9-Torque/angle curves of different sizes of in-plane rotation tests

To determine $\alpha$ and $\beta$, any two curves can be used. Here, the curve of $14.68 \mathrm{~mm}(0.578 \mathrm{in}$.) offset with $1134 \mathrm{~N}(255 \mathrm{lbf})$ yield force and the curve of $7.36 \mathrm{~mm}(0.2897 \mathrm{in}$.) offset with $2246 \mathrm{~N}$ (505 lbf) yield force were chosen first:

$$
\begin{aligned}
& \left(\frac{1134}{5782}\right)^{\alpha}+\left(\frac{1134 \times 14.68}{16947}\right)^{\beta}=1 \\
& \left(\frac{2246}{5782}\right)^{\alpha}+\left(\frac{2246 \times 7.36}{16947}\right)^{\beta}=1 .
\end{aligned}
$$

Solving the last two equations numerically, both $\alpha$ and $\beta$ were found to be very close to 2 . To verify this, another two curves (the curve of $21.24 \mathrm{~mm}(0.8362$ in.) offset with $756 \mathrm{~N}$ (170 lbf) yield force and the curve of $3.98 \mathrm{~mm}(0.1567 \mathrm{in}$.) offset with $3336 \mathrm{~N}(750 \mathrm{lbf})$ yield force) were used:

$$
\begin{aligned}
& \left(\frac{756}{5782}\right)^{2}+\left(\frac{756 \times 21.24}{16947}\right)^{2} \cong 1 \\
& \left(\frac{3336}{5782}\right)^{2}+\left(\frac{3336 \times 3.98}{16947}\right)^{2} \cong 1
\end{aligned}
$$

This confirms that the force-based failure rule works reasonably well on a single spot weld that is under static in-plane loading. To see whether it works for a group of spot welds, a new test fixture was designed.

\section{Combined Load Test II-Box Test}

A spot weld arrangement being widely used for rotationresistant design in the auto industry is shown in Fig. 12. This pattern of spot weld contains four spot welds located at the corners of a 2 in. $\times 2$ in. square area and one spot weld located at the center of the square. Auto designers believe that this pattern of spot welds will restrain the sheet metals from in-plane rotation.

By putting this group of spot welds into a $1.58 \mathrm{~mm} / 0.93 \mathrm{~mm}$ $(0.0622$ in. $/ 0.0366$ in.) box type of test fixture (see Fig. 12) and pulling it with a tensile machine, it was found that the whole cluster of spot welds could take only about $1334 \mathrm{~N}$

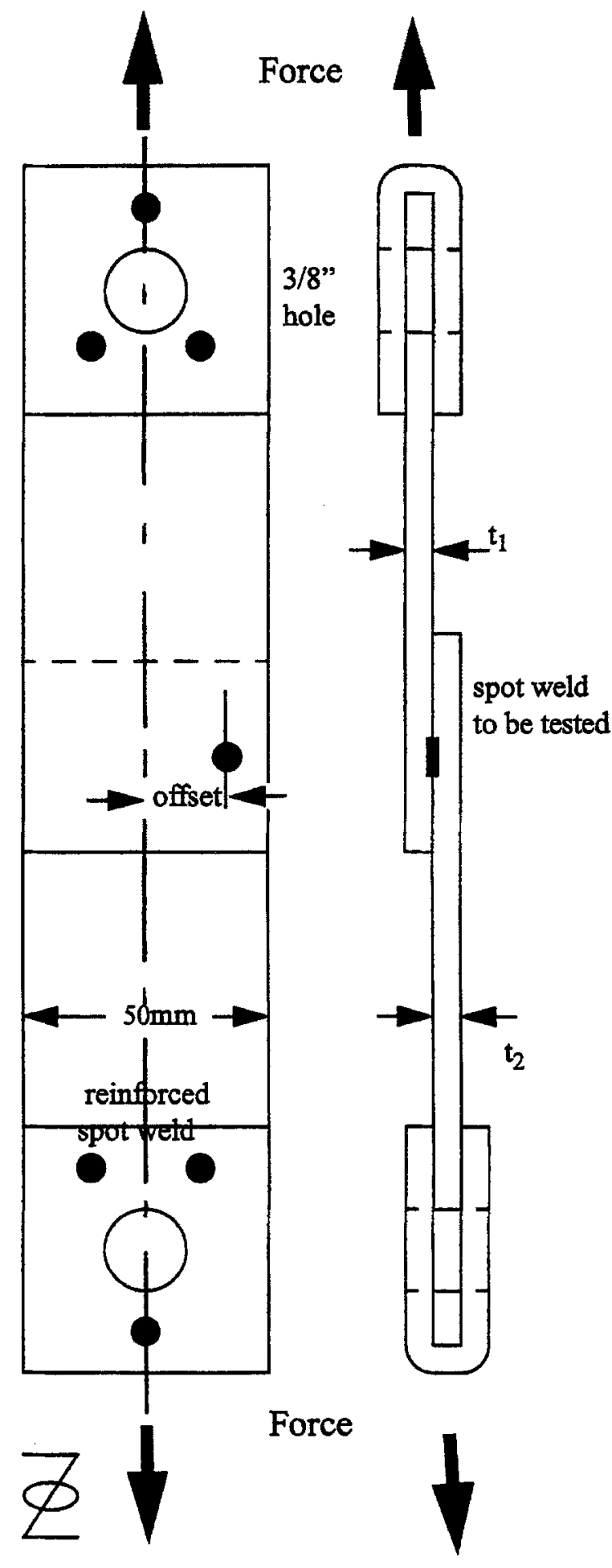

Fig. 10-Offset test coupon

( $300 \mathrm{lbf}$ ) force before it yielded. This yielding force was far below single spot weld shear strength, which is about 2376 $\mathrm{N}$ (534 lbf). If the external applied load were converted to tensile load only to each spot weld, the whole box would be expected to sustain a load of $2376 \mathrm{~N}$ (534 lbf) or more. Apparentiy, this group of spot welds was under a load condition that is more than just shear mode.

To observe the deformation of each spot weld, straight lines were drawn to the spot welds before testing. After 


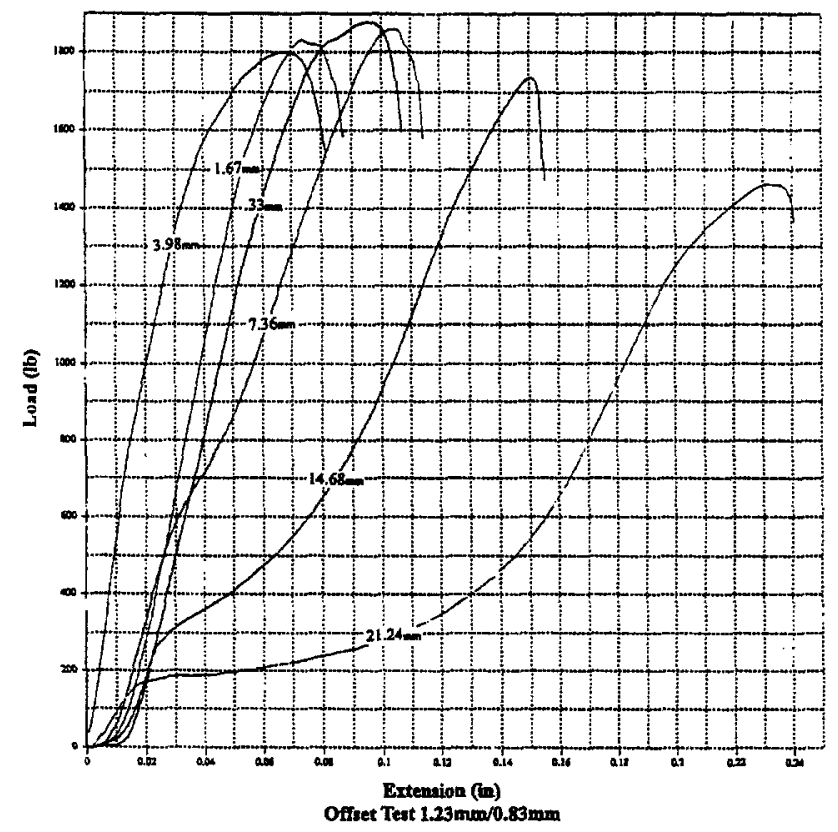

Fig. 11-Force/deflection curves of offset test
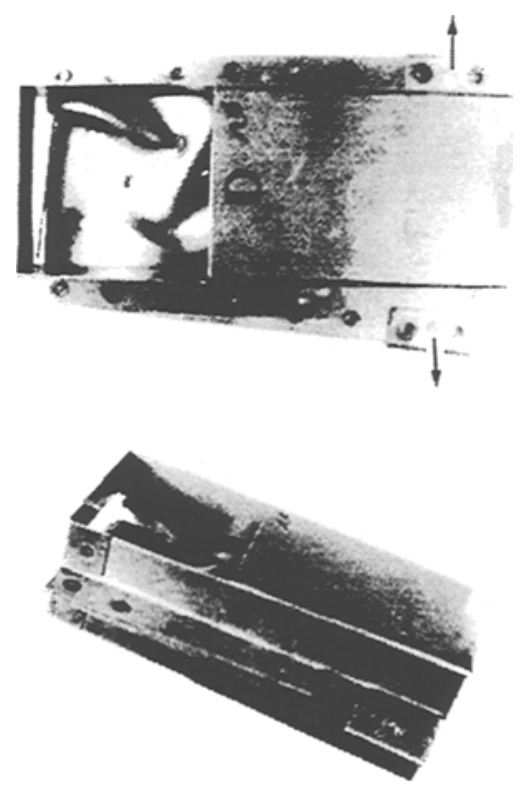

Fig. 12-Box coupon for in-plane loading test

testing, most of these straight lines had been shifted and rotated (see Fig. 13). Comparing these deformed lines with the similar test results published in Ref. 10 for the "pure" in-plane rotational tests, it becomes obvious that the spot welds tested in Fig. 12 were under a combination of tensile and rotational modes. To quantify this, finite element analysis was used.

A static, linear finite element analysis (NASTRAN CBEAM) was used to find the applied nodal forces at each spot weld. Under a $1000 \mathrm{~N}$ ( $224.8 \mathrm{lbf})$ applied loading condition, the nodal forces on each spot weld shown in Fig. 12 are depicted in Fig. 14. Comparing Figs. 13 and 14, we found that there are very good correlations between testing and finite element analysis. First, all of the spot welds had a clockwise rotation. Second, both of the left spot welds (A

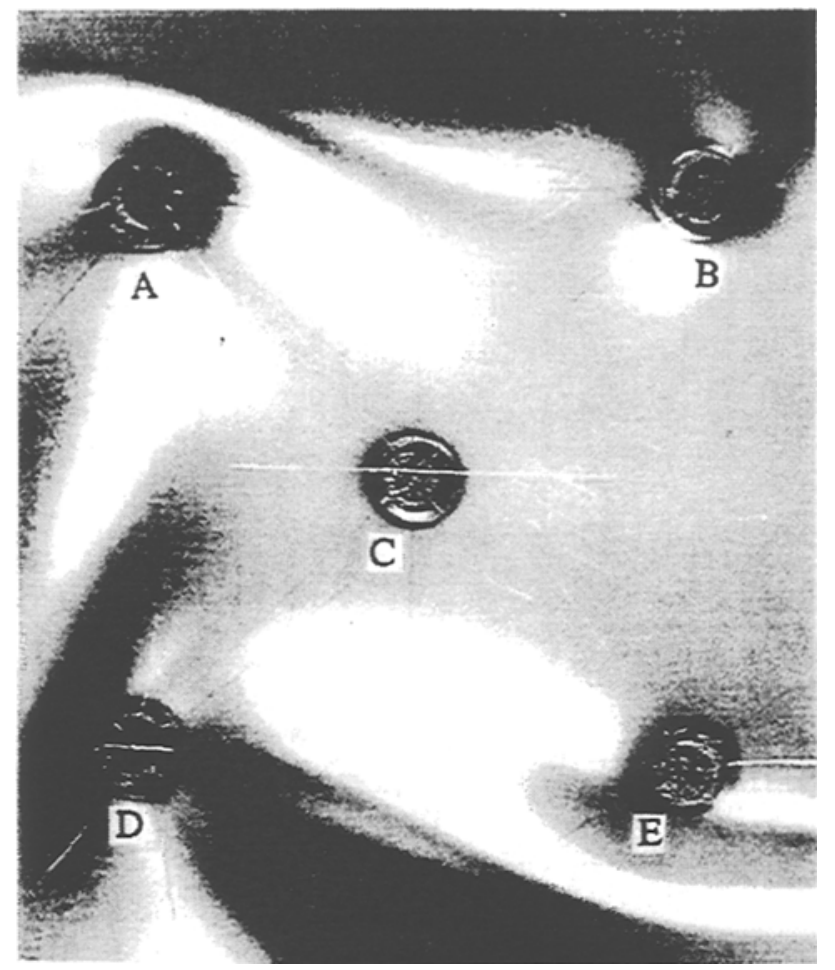

Fig. 13-Deformed spot welds of a box coupon under combined in-plane tensile and rotational loading

and $D$ ) were shifted upward, and both of the right spot welds ( $B$ and $E$ ) were shifted downward. Third, both of the upper spot welds ( $A$ and $B$ ) were shifted to the right, and both of the lower spot welds ( $D$ and $E$ ) were shifted to the left. Finally, the center spot weld $(C)$ rotated but was not shifted to any direction. This is because the shear force of $\mathrm{C}$ was not big enough to cause a permanent translational deformation. All these permanent deformations match the finite element force distributions very well.

To determine the correctness of the failure criterion quantitatively, a detailed calculation was made on spot weld A. From the component depicted in Fig. 14, the resultant shear force at $A$ is found to be

$$
1310.8=\sqrt{900.9^{2}+952 \cdot 1^{2}} .
$$

The in-plane rotation moment of spot weld $A$ is $3869.9 \mathrm{~N}-\mathrm{mm}$ (34.25 lbf-in.). From tensile test and in-plane rotation test, it is found that for $1.58 \mathrm{~mm} / 0.93 \mathrm{~mm}(0.0622 \mathrm{in} . / 0.0366 \mathrm{in}$.) mild steel, the shear strength $F_{s}$ is $2376 \mathrm{~N}$ (534 lbf) and the in-plane rotation strength $M_{t}$ is $7440 \mathrm{~N}-\mathrm{mm}$ (65.85 lbf-in.). Putting these numbers into the proposed failure rule

$$
\left(\frac{1310.8 X}{2376}\right)^{2}+\left(\frac{3869.9 X}{7440}\right)^{2}=1.0
$$

yields $X=1.3189$. This means that the calculated yield loading is $1318.9 \mathrm{~N}$ (296.5 lbf), which correlates very well with the tested value of $1334 \mathrm{~N}$ ( $300 \mathrm{lbf}$ ).

\section{Conclusion}

This paper demonstrates the existence of in-plane loaded spot weld failures in a real-world structure (see Fig. 1). With 


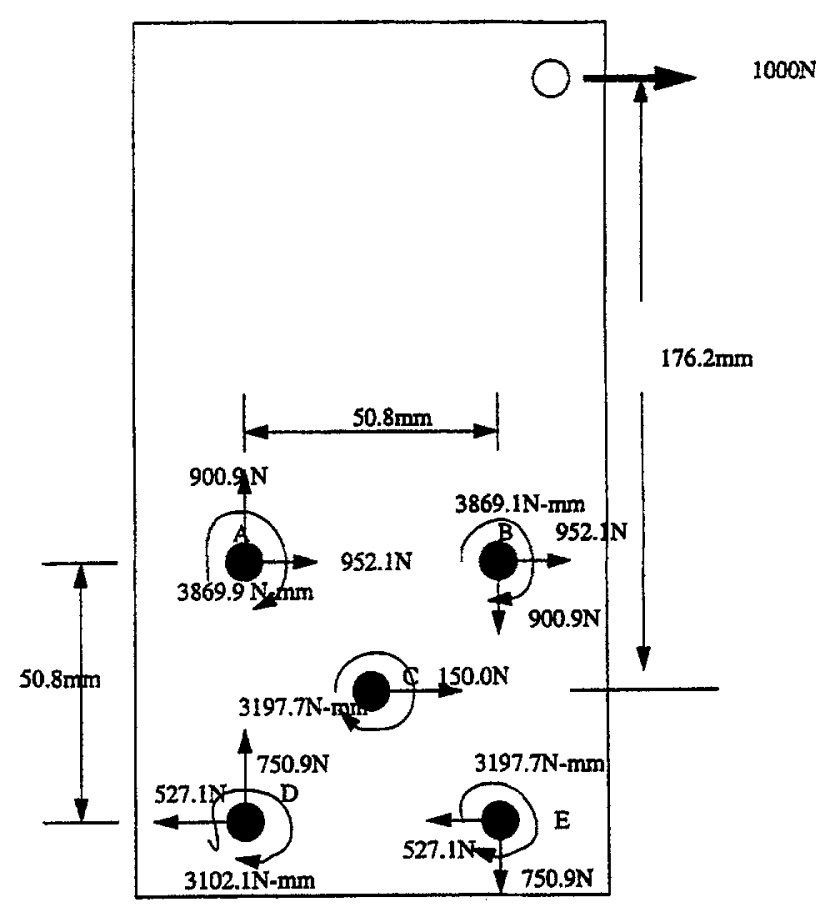

Equilibrium Check :

$$
\begin{aligned}
\Sigma F_{x}= & 952.1 * 2+150.0-527.1 * 2=1000.0 \\
\Sigma F_{y}= & 900.9-900.9+750.9-750.9=0.0 \\
\Sigma M_{c}= & -900.9 * 50.8-750.9 * 50.8-952.1 * 25.4 * 2-527.1 * 25.4 * 2 \\
& -3869.9-3869.1-3197.7-3102.1-3102.0 \\
= & 1761956.6=1000 * 176.2
\end{aligned}
$$

Fig. 14-Results of finite element analysis

a proposed force-based failure criterion, single and multiple spot weld coupon tests to quantify the failure were performed and found to compare well with the finite element analysis prediction. In addition, the EDM cut samples were examined to distinguish the failure process developments of these different failure modes.

Most important, this paper illustrates the complete process and procedures needed to evaluate spot weld failures under in-plane loadings. To decompose the combined failure, the tensile test was used to determine the spot weld shear strength $F_{s}$, and the in-plane rotation test was used to determine the spot weld torsion strength $M_{t}$. Once $F_{s}$ and $M_{t}$ were determined, the offset test was used to determine the simple failure criterion. Finally, a test coupon containing a group of spot welds was tested and analyzed to further validate the correctness of the force-based failure criterion.

By introducing the in-plane failure mode, causes of spot weld failures are revealed that are important in real structure design. Without accounting for the in-plane rotation mode, design conclusions made for spot-welded structures are questionable when that loading mode becomes dominant.

\section{References}

1. Radaj, D., "Structural Stress, Notch Stress and Stress Intensity Approach for Assessment of Fatigue Strength of Spot Welded Joints," International Institute of Welding Annual Assembly (1989).

2. McMahon, J.C. and Lawrence, F.V., "Fatigue Crack Initiation and Growth in Tensile-shear Spot Weldments," Fatigue and Fracture Testing Weldments, ASTM STP 1058, American Society for Testing and Materials, Philadelphia, 47-77 (1990).

3. Swellam, H.M., Kurath, P., and Lawrence, F.V., "Electric-potentialdrop Studies of Fatigue Crack Development in Tensile Shear Spot Welds," ASTM STP 1122, American Society for Testing and Materials, Philadelphia, 383-401 (1991).

4. Kurath, P. and Fatemi, A., "Multiaxial Fatigue Life Predictions under the Inftuence of Mean Stress," Trans. ASME, J. Eng. Mat. Tech., 110, 380-388 (1988).

5. Brown, M.M. and Miller, K.J., "Theory for Fatigue under Multiaxial Stress-strain Condition," Proc. Inst. Mech. Engineers, 187, 745-755 (1973).

6. Andreas, R., Klaus, S., and Vatroslav, G., "Computer Aided Dimensioning of Spot Welded Automotive Structures," SAE Paper No. 950711 (1995).

7. Kurath, P., "Multiaxial Fatigue Criteria for Spot Welds," SAE Paper No. 920668 (1992).

8. Lee, Y.L., Wehner, T.J., Lu, M.W., Morrissett, T.W., and Pakalnins, E., "Ultimate Strength of Resistance Spot Weld Subjected to Combined Tension and Shear," J. Test. Eval., 26, 213-219 (1998).

9. Wung, P. and Stewart, W., "Method of Analyzing Spot Welded Structures." U.S. Serial No. 09/347558 patent pending (1999).

10. Wung, P., Walsh, T., Ourchane, A., and Stewart, W., "The Ignored Failure Mode: Spot Weld under In-plane Rotation (Physical Test)," SAE Paper No. 1999-01-3212 (1999).

11. Wung, P., "A Force-based Failure Criterion for Spot Weld Design," EXPERIMENTAL MECHANICS, 41, 107-113 (2001). 